\title{
NÍVEIS DE PROTEÍNA DIGESTÍVEL EM DIETAS PARA ACARÁ-BANDEIRA PTEROPHYLLUM SCALARE (GUNTHER, 1862)
}

Levels of digestible protein in diets for the freshwater angelfish Pterophyllum scalare (Gunther, 1862)

\author{
Welliton G. De Franca, Fabricio Martins Dutra, Luana Cagol, Maria Luiza Ruiz, Pedro Gusmão Borges \\ Neto, Leandro Portz
}

${ }^{1}$ Correspondência: wellitonnf@gmail.com

RESUMO: O objetivo deste estudo foi avaliar o efeito de níveis de proteína digestível - PD na dieta sobre o desempenho do acará-bandeira (Pterophyllum scalare). O delineamento foi inteiramente casualizado, composto por cinco tratamentos (30, 32, 34, 36 e 38\% de PD) e quatro repetições, durante 60 dias. Foram utilizados 200 peixes, distribuídos em 20 aquários de $45 \mathrm{I}$ cada, em sistema de recirculação, com temperatura controlada e fotoperíodo de $12 \mathrm{~h}$. Os animais foram submetidos a uma dieta isoenergética $3200 \mathrm{Kcal} . \mathrm{kg}-1$ de energia digestível e, contendo níveis crescentes de PD. Foram analisados os índices zootécnicos levando em consideração: ganho de peso, conversão alimentar aparente, taxa de eficiência proteica, taxa de crescimento específico e conversão alimentar aparente. Os resultados foram submetidos à análise de variância (ANOVA), seguida pelo teste de Tukey $(\mathrm{P}<0,05)$ e análise de regressão. $\mathrm{Na}$ avaliação dos índices zootécnicos, os animais alimentados com a dieta contendo $32 \%$ de PD apresentaram desempenho inferior aos demais. Os valores de $34 \%, 36 \%$ e $38 \%$ de PD não diferiram entre si $(P>0,05)$. Dessa forma, conclui-se que juvenis de acará-bandeira podem ser alimentados com $34 \%$ de PD sem comprometer o desempenho zootécnico, considerando o elevado custo associado à inclusão de proteína a níveis superiores.

Palavras-chave: desempenho produtivo; nutrição; peixes ornamentais

ABSTRACT: The aim of this study was to evaluate the effect of levels of digestible protein - DP in the diet on the performance of the Angelfish (Pterophyllum scalare). The design was completely randomized, consisting of five treatments $(30 \%, 32 \%$, $34 \%, 36 \%$ and $38 \%$ of DP) and four replications for 60 days. Two hundred fish were distributed in 20 tanks of 45 liters each in a recirculation system with controlled temperature and photoperiod of $12 \mathrm{~h}$ (light / dark). The zootechnical indexes were analyzed taking into consideration: weight gain, feed conversion, protein efficiency rate, specific growth rate and apparent feed conversion. The results were submitted to analysis of variance (ANOVA), followed by the Tukey test $(\mathrm{P}<0.05)$ and regression analysis. In the evaluation of the zootechnical indexes, the animals fed a diet containing $32 \%$ of DP presented inferior performance to the others. The values of $34 \%, 36 \%$ and $38 \%$ of DP did not differ from each other $(P>0.05)$. Thus, it can be concluded that the juvenile angelfish can be fed with $34 \%$ PD without compromising the zootechnical performance, considering the high cost associated with the inclusion of protein at higher levels.

Key Words: nutrition; ornamental fish; productive performance; 


\section{INTRODUÇÃO}

O comércio de peixes ornamentais é considerado um dos setores mais lucrativos da piscicultura e vem se expandindo rapidamente com o aumento da demanda mundial por esses animais (Lima et al., 2001), bem como, se apresenta como um componente significativo do comércio internacional (Ribeiro et al., 2007). Segundo Chapman, et al. (1997) dentre a diversas espécies de peixes brasileiros, 0 acará-bandeira (Pterophyllum escalare), o acará disco (Simphysodon spp.), o oscar (Astronotus ocellatus) e o cardinal tetra (Paracheirodon axelrodi), estão entre as 20 principais espécies de peixes ornamentais mais importados pelos norte-americanos.

No Brasil, a atividade teve início em 1922 (INSTITUTO DE PESCA, 2013). Entretanto, após 80 anos de difusão da atividade no país, em sua grande maioria ainda é realizada por meio de extrativismo, sendo o Brasil um dos principais fornecedores de espécies de peixes ornamentais de clima tropical para o mercado externo (SEAP, 2008).

Dentre as espécies de peixes ornamentais, 0 acará-bandeira, $P$. scalare, se destaca por ser um dos mais belos, mais vendidos e também mais populares peixes ornamentais de águas tropicais (Chapman et al., 1997). Originário da bacia Amazônica é amplamente distribuído, sendo encontrada no Peru, Colômbia, Guianas e Brasil (Ribeiro et al., 2007). Pertence à grande família dos Ciclídeos, cuja principal característica é possuir a linha lateral interrompida (Lima, 2003). Apresenta 0 corpo comprimido lateralmente, forma triangular, criada por suas nadadeiras dorsal e anal, que são fortes e alongadas, e cor prateada, que contrasta com listras verticais pretas e nadadeiras ventrais modificadas, finas e longas. Adaptado a águas duras de $\mathrm{pH}$ levemente ácido, pode chegar a $15 \mathrm{~cm}$ de comprimento, é calmo e territorialista. Quando jovem, vive em cardume e estabelece hierarquia. Normalmente são encontradas na natureza próximas a raízes, madeiras e vegetação submersa (Cacho et al., 1999).

Visando 0 fornecimento de conhecimentos para o preenchimento das lacunas produtivas existentes para a espécie, alguns estudos vêm sendo realizados em áreas vitais de sua produção como reprodução (Cacho et al., 1999), nutrição (Rodrigues e Fernandes, 2006; Zuanon et al., 2006; Ribeiro et al., 2007), sistema de produção (Ribeiro et al., 2008) e controle de doenças (Alves et al., 2001; Fujimoto et al., 2006; Ribeiro et al., 2010; Gonçalves Júnior et al., 2013).

No entanto, estudos mais detalhados sobre a exigência nutricional ainda são necessários, tendo em vista a escassez de estudos voltados para piscicultura ornamental em relação aos de peixes de corte (Shim e Chua, 1986). Sendo assim, o objetivo deste estudo foi avaliar o efeito de diferentes níveis de proteína digestível na dieta sobre o desempenho do acará-bandeira ( $P$. scalare) tendo em vista que, não existe nenhuma informação sobre a exigência em proteína digestível para a espécie.

\section{MATERIAL E MÉTODOS}

O estudo foi conduzido no Laboratório de aquariologia da Universidade Federal do Paraná - Setor Palotina por um período de 60 dias.

Foram utilizados 200 juvenis de acará-bandeira ( $P$. scalare), com peso de $0,39 \pm 0,11 \mathrm{~g}$ e comprimento total médio inicial de $2,88 \pm 0,30 \mathrm{~cm}$. Os animais foram distribuídos em 20 aquários com volume útil de 45I, dotados de recirculação, aeração constante e foto período controlado 
12:12h, em delineamento inteiramente casualizado, composto por cinco tratamentos $(30 \%, 32 \%, 34 \%, 36 \%$ e $38 \%$ de proteína digestível) e quatro repetições.

Os juvenis foram alimentados a uma taxa de $4 \%$ da biomassa total, divididas em duas alimentações diárias (às 8:30h e 16:30h). Foi realizado diariamente a sifonagem das unidades experimentais para retirada de fezes e restos de alimentação. Quinzenalmente os peixes foram submetidos a uma biometria para correção da taxa alimentar.

Os animais receberam dietas isoenergéticas $\left(3.200 \mathrm{Kcal}\right.$ de $\left.\mathrm{ED} . \mathrm{Kg}^{-1}\right)$ conforme resultados encontrados por Frei (2011), contendo níveis crescentes de proteína digestível $(30 \%, 32 \%, 34 \%$ e $36 \%$ PD), conforme formulação apresentada na Tabela 1.

Tabela 1- Composição percentual das dietas experimentais para juvenis de acará-bandeira, P. scalare, com níveis crescentes de proteína digestivel (PD).

\begin{tabular}{lccccc}
\hline \multirow{2}{*}{\multicolumn{1}{c}{ Ingredientes }} & \multicolumn{5}{c}{ Dieta (\%) } \\
\cline { 2 - 6 } & $30^{*}$ & 32 & 34 & 36 & 38 \\
\hline Farelo Soja & $43,19^{* *}$ & 43,25 & 37,00 & 33,00 & 51,30 \\
Farinha Peixe & 19,80 & 24,50 & 35,25 & 44,75 & 34,70 \\
Fubá Milho & 12,00 & 9,50 & 6,50 & 3,00 & 8,00 \\
Farelo Trigo & 14,76 & 13,00 & 12,00 & 11,00 & 1,00 \\
Amido Milho & 5,00 & 5,00 & 5,00 & 5,00 & 1,25 \\
DL - Metionina & 0,20 & 0,20 & 0,20 & 0,20 & 0,20 \\
Oleo Soja & 3,00 & 2,50 & 2,50 & 2,00 & 2,50 \\
Fosfato Bicálcice & 1,50 & 1,50 & 1,00 & 0,50 & 0,50 \\
Premi ${ }^{0 * * *}$ & 0,50 & 0,50 & 0,50 & 0,50 & 0,50 \\
BHT & 0,05 & 0,05 & 0,05 & 0,05 & 0,05 \\
\hline${ }^{*}$ Porcentagem de proteína digestivel; * ${ }^{* *}$ Composição calculada (\%); ${ }^{* * *}$ Niveis de garantia
\end{tabular}

por quilograma: Vit. $A=2.500 .000$ UI; vit. $\mathrm{D} 3=600.000 \mathrm{UI}$; vit. $\mathrm{E}=37.500 \mathrm{UI}$; vit. $\mathrm{K} 3=$

$3.750 \mathrm{mg}$; vit $C=50000 \mathrm{mg}$; vit. $B 1=4000 \mathrm{mg}$; vit. $B 2=4000 \mathrm{mg}$; vit. $B 6=4000 \mathrm{mg}$; vit. $B 12=4000 \mathrm{mg} ;$ pantetenato de cálcio $=12000 \mathrm{mg} ;$ biotina $=15 \mathrm{mg}$; ácido fólico $=1250$ $\mathrm{mg}$; niacina $=22500 \mathrm{mg}$; cobre $=2500 \mathrm{mg}$; zinco $=22500 \mathrm{mg}$; selênio $=87,5 \mathrm{mg}$; cobalto $=125 \mathrm{mg}$; manganês $=12500 \mathrm{mg}$; ferro $=15000 \mathrm{mg} ;$ B.H.T. $=15000 \mathrm{mg}$.

As dietas foram formuladas com o programa disponibilizado pelo Centro de Aquicultura da Universidade Estadual Paulista "Júlio de Mesquita Filho" (CAUNESP), e processada seguindo a metodologia utilizada por Ferrari et al. (2004) para moagem, umedecimento e mistura. As rações foram processadas em peletizadora experimental, obtendose pellets com aproximadamente $0,5 \mathrm{~mm}$ de diâmetro médio, sendo secos em estufa de recirculação a $60^{\circ} \mathrm{C}$, durante 24h. Ao fim do processo de secagem, amostras $(50 \mathrm{~g})$ de cada ração foram coletadas e encaminhadas para análise de composição química, sendo o restante conservado a $-4^{\circ} \mathrm{C}$.

A análise química das amostras de ração (Tabela 2) foi realizada, em triplicata, no Laboratório de Qualidade de Alimentos da Universidade Estadual do Oeste do Paraná, Campus Toledo, Paraná. A metodologia de análise seguiu as recomendações propostas por Helrich (1980).

Tabela 2 - Composição química das dietas experimentais com diferentes níveis de
proteína digestivel, utilizada para juvenis de acará-bandeira, P. Scalare.

O registro das principais variáveis de qualidade de água foi realizado diariamente com o uso de aparelhos digitais microprocessados para os seguintes parâmetros: Oxigênio dissolvido, temperatura e $\mathrm{pH}$. A amônia foi determinada segundo Koroleff (1976), nitrito segundo Mackereth et al. (1978) a cada 10 dias.

Para avaliar o desempenho dos peixes, duas biometrias foram realizadas: a primeira no início e a segunda ao final do período experimental. O ganho de peso dos peixes (GP) foi calculado pela diferença entre os resultados de peso médio final e inicial dos peixes de cada unidade experimental $(G P=$ peso final peso inicial).

As demais análises seguiram recomendações de Takeuchi e Watanabe (1988) e Tacon (1990), sendo, para determinação da Taxa de Crescimento Especifica (TCE), foi empregada a seguinte equação:

(In) Peso médio final -

(In) Peso médio inicial

$\operatorname{TCE}(\% / d i a)=$ $X 100$ (dia) 
In = logaritimo neperiano

A Conversão Alimentar Aparente (CAA) foi calculada dividindo-se os resultados de consumo de ração pelo ganho de peso dos peixes.

$\mathrm{CAA}=\frac{\text { Consumo de ração }}{\text { Ganho de peso }}$

A Taxa de Eficiência Protéica (TEP) foi obtida pela relação entre ganho de peso dos peixes e o consumo de proteína no período experimental:

TEP $=\frac{\text { Ganho de peso }}{\begin{array}{l}\text { Consumo de ração } x \% \mathrm{PD} \text { da } \\ \text { dieta }\end{array}}$

A Sobrevivência (S) foi determinada pela expressão:

$S(\%)=\frac{\text { Número de peixes final }}{\text { Número de peixes inicial }} \times 100$

A análise estatística foi submetida à verificação de normalidade através do teste de Shapiro-Wilk e a homogeneidade através do teste de Levene. Após atendido os dois pressupostos, foi aplicada a análise de variância (ANOVA), ao nível de significância de 5\%, seguida pelo Teste de Tukey $(\mathrm{P}<0,05)$ para comparação de médias utilizando o programa Statistica 7.0 (Statsoft Inc, 2004), e posteriormente aplicada a regressão linear para ganho de peso.

\section{RESULTADOS E DISCUSSÃO}

(SB) não apresentou diferenças estatísticas significativas $(P>0,05)$. No entanto, a sobrevivência observada variou de 70 a $97 \%$ entre os tratamentos Sobrevivências semelhantes foram encontradas por Luna-Figueroa (1999) que relatou sobrevivência média de $86 \%$ ao trabalhar com alimento vivo. Erdogan e Olmez (2009), observaram sobrevivência de 77 a 93\% com suplementação enzimática em dietas e Koca et al., (2009), relataram sobrevivência de 87 a $100 \%$ em estudo com diferentes tipos de alimentação. A mortalidade observada neste estudo foi atribuída à espécie, principalmente devido a condição territorialista, a qual é demostrada pelo comportamento de competição por área e alimento.

Para os demais parâmetros zootécnicos o tratamento com 32\% proteína digestível (PD) apresentou desempenho menor $(P<0,05)$ quando comparado aos tratamentos de $34 \%$, $36 \%$ e $38 \%$ de PD para peso final (PF), taxa de crescimento especifica (TCE) e conversão alimentar aparente (CAA). Quanto aos índices de comprimento final (CF), taxa de eficiência proteica (TEP) e o ganho de peso (GP), estes resultados estão sumarizados na tabela 3.

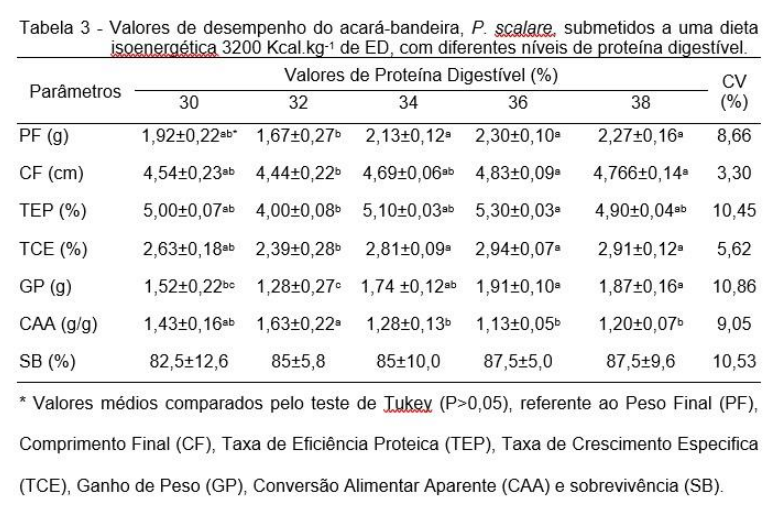

Os dados de peso final e comprimento final (Figura 1) apresentaram um comportamento semelhante, ou seja, o tratamento com menor peso final também apresentou o menor comprimento ( $32 \%$ de PD), os demais tratamentos não apresentaram diferenças entre si. Esse comportamento pode ser justificado por conta da maior porcentagem e proteína de origem vegetal no tratamento contendo $32 \%$ de $P D$, à qual pode ter 
sido responsável pela redução da palatabilidade e consequentemente consumo de ração pelos peixes.

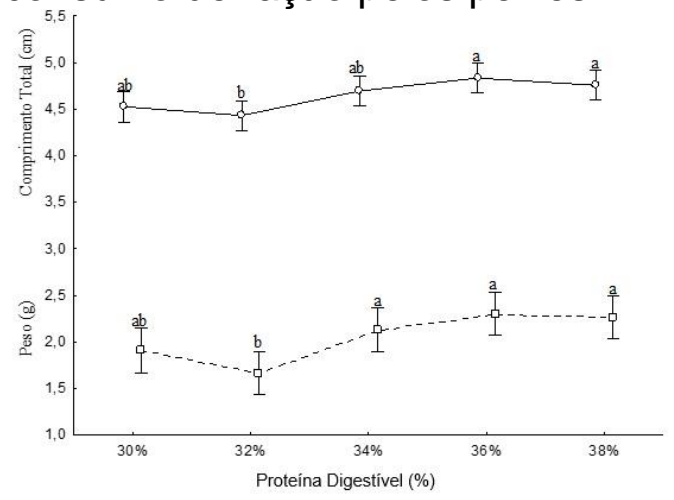

Figura 1 - Média do peso $(\mathrm{g})$ e do comprimento total $(\mathrm{cm})( \pm$ D.P) de $P$. scalare alimentados com diferentes niveis de proteína digestivel, durante 60 dias.

Com relação ao índice de crescimento específico os tratamentos com 30 e $32 \%$ de PD apresentam os piores resultados, diferindo entre os demais tratamentos. Os valores foram ligeiramente maiores do que os encontrados por Zuanon et al. (2006), que foi de $2,31 \%$ e $2,61 \%$ para $34 \%$ e $38 \%$ de PB. Entretanto esteve mais baixo do que o observado por Oliveira (2009), que foi de $2,35 \%$ para 29 e $32 \%$ PB. Uma possível explicação para tal variação pode ser direcionada na diferença de idade e variedade dos animais utilizados em cada trabalho, onde no presente estudo, os animais utilizados foram menores e mais jovens, fase em que os animais apresentam um crescimento acentuado em um curto período de tempo.

Para análise de ganho de peso foi utilizada a regressão linear $(P<0,05)$. Os resultados obtidos nos tratamentos em que os animais foram alimentados com 30\% e 32\% PD não foram satisfatórios, apresentando ganho de peso médio de $1,52 \mathrm{~g}$ e $1,28 \mathrm{~g}$ respectivamente. Os valores 34\%, 36\% e $38 \%$ de PD corresponderam ao ganho de peso médio de $1,74 \mathrm{~g}, 1,91 \mathrm{~g}$ e 1,87 $\mathrm{g}$ e não apresentaram diferença estatística significativa. No entanto, o o ganho de 1,91 g obtido com 36\% PD pode ser correlacionado com a maior porcentagem de fonte proteica de origem animal adicionada a esta dieta.

As médias de ganho de peso neste trabalho foram superiores às registradas por Luna-Figueroa (1999) que relataram ganho de peso de 0,63 $\mathrm{g}, 0,68 \mathrm{~g}$ e 0,78 $\mathrm{g}$ em dietas contendo $27 \%$, $43 \%$ e $45 \%$ de PB.Zuanon et al. (2006) registram ganho de peso médio de 1,39 g, 1,78 g, $1,53 \mathrm{~g}$ e 1,53 g em níveis 34\%, 38\%, $42 \%$ e $46 \%$ de $\mathrm{PB}$, respectivamente. Assim como observado por Zuanon et al. (2009) que foi de $1,51 \mathrm{~g}, 1,57 \mathrm{~g} \mathrm{e}$ 1,49 g para níveis de $\mathrm{PB}$ de 26, 30 e $34 \%$. A variação em ganho de peso na mesma espécie pode ser influenciada por variações na densidade de peixes, a taxa e frequência na alimentação durante a fase de desenvolvimento do animal e a qualidade da proteína utilizada. Além da diferença na formulação das dietas, no presente estudo, havia maior porcentagem de proteína de origem animal, a variação do tamanho inicial dos animais foi decisiva para este fator. A utilização de animais com menor tamanho inicial e idade, influenciou o resultado de crescimento e ganho de peso dos peixes, considerando que esta é a fase onde o crescimento é mais acentuado, o que pode ser utilizado para explicar a grande diferença quando comparados com resultados já descritos na literatura.

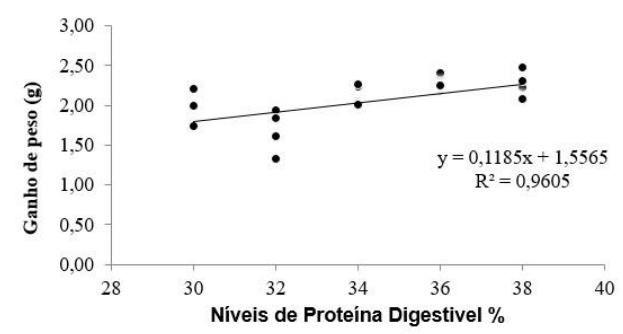

Figura 2: Regressão linear do Ganho de Peso em gramas (g) e nivel de proteina digestivel da dieta (\%) de juvenis de acará-bandeira (Pterophyllum scalare) alimentados durante 60 dias.

Os tratamentos com $34 \%, 36 \%$ e $38 \%$ de PD não apresentaram 
diferenças $(P>0,05)$, o tratamento que apresentou maior contraste foi o de $36 \%$ de PD, apresentando menor valor de CAA, de 1,13:1. Os tratamentos com 30 e $32 \%$ de PD foram insatisfatórios para conversão alimentar, com valores de 1,43:1 e 1,63:1 respectivamente. Ribeiro et al. (2007) observaram em estudo com níveis de $26 \%$ a $32 \%$ de PB uma conversão alimentar de 2,5 a 1,5 , enquanto Zuanon et al. (2006) obtiveram valores de CAA entre 2,09 a 2,58, em estudo com nível de proteína bruta entre 34 a $46 \%$. Ambos os resultados são insatisfatórios em relação ao obtido no presente trabalho. Entretanto, essa melhor eficiência na CAA encontrada pode estar diretamente relacionada à maior presença de proteína animal na formulação da dieta.

\section{CONCLUSÃO}

Os diferentes níveis de proteína digestível da dieta influenciaram no desempenho de juvenis de acarábandeira. As dietas com nível de 34 e $36 \%$ de PD apresentam melhores resultados em todos os índices observados. Entretanto, ao considerarmos a viabilidade econômica, o nível de $34 \%$ de PD deve ser considerado como 0 ideal para formulação de rações, por resultar em menor custo de produção.

\section{NOTA INFORMATIVA}

\section{O presente}

foi aprovado pelo comitê de ética, sob protocolo no 41/ 2016.

\section{REFERÊNCIAS}

RAMOS ALVES, D, LUQUE, J. L., e RODRIGUES PARAGUASSU, A. Metacercárias de Clinostomum marginatum (Digenea: Clinostomidae) em acará-bandeira Pterophyllum scalare
(Osteichthyes: Cichlidae) no estado do Rio de Janeiro, Brasil. Parasitología al día, v.25, p.70-72. 2001.

AXELROD, H. R.; BURGESS, W. E.; PRONEK, N.; WALLS, J. G. Dr. Axelrod's Atlas of Freshwater Aquarium Fishes. T. F. H. Publications, Inc. New Jersey, USA, 1152 p. 1997.

BONFIM, M. A. D.; LANNA, E. A. T.; SERAFINI, M. A. et al. Proteína bruta e energia digestível em dietas para alevinos de curimbatá (Prochilodus affins). Revista Brasileira de Zootecnia, Viçosa, v. 34, n. 6, p. 17951806. 2005.

CACHO, M.S.R.F.; YAMAMOTO, M.E.; CHELLAPPA, S. Comportamento reprodutivo do acara-bandeira, Pterophyllum scalare (Osteichthyes, Cichlidae). Revista Brasileira de Zoologia, São Paulo, v.16, n.1, p. 653664. 1999.

CHAPMAN, F. A.; FITZ-COY, S.; THUNBERG, J. T. United States of America International Trade in Ornamental Fish. Journal of the the word Aquaculture Society, Baton Rouger, v.28, n.1, p.1-10.C.1997.

CRUZ, M. E. P.; SALAS, I. M.; QUEZADAS, $H$. O. Frecuencia de desove de diferentes variedades del Pez Angel Pterophyllum scalare (Pisces: Cichlidae). Revista Aquatic, Zaragoza, n. 16, [s/p]. 2002.

EBLING, E. D.; BEM, L. H.; BRUM, O. B.; et al. Desenvolvimento do Grumatã (Prochilodus lineatus) em viveiros de criação. Vivências, v.9, n.16, p.115122. 2013.

ERDOGAN, F.; OLMEZ, M. Effects of enzyme supplementation in diets on growt and feed utilization in angel Fish, Pterophyllum scalare. Journal of Animal and Veterinary Advance, v.8, n.9, p.1740-1745. 2009.

FERRARI, J. E. C.; BARROS, M. M.; PEZZATO, L. E. et al. Níveis de cobre em dietas para tilápia do Nilo 
(Oreochromis niloticus). Acta

Scientiarum, Maringá, v.26, p.429-436. 2004.

FREI, G. R. Avaliação da energia digestível em dietas de acarábandeira (Pterophyllum scalare). 2001. 34 f. Trabalho de Conclusão de Curso (Bacharelado em Engenharia de Pesca). Universidade Estadual do Oeste do Paraná - Toledo, PR. 2011.

FUJIMOTO, R. Y.; VENDRUSCOLO, L.; SCHALCH, S. H. C.; MORAES, F. R. Avaliação de três diferentes métodos para o controle de monogenéticos e Capillaria sp. (Nematoda: Capillariidae), parasitos de acará-bandeira (Pterophyllum scalare liechtenstein, 1823). Boletim do Instituto de. Pesca, São Paulo, v. 32, n.2, p.183 - 190. 2006.

GALLI, L. F.; TORLONI, C. E. C. Criação de peixes. 3. ed. Sao Paulo: Nobel, 119p. 1987.

GONÇALVES. A. P.; CAMARGO, M.; CARNEIRO, A, T. et al. A pesca de peixes ornamentais. In: Camargo e Gillardi (Ed.) Entre a terra, as águas e os pescadores do médio Rio Xingu. 235p. 2009.

GONÇALVES JÚNIOR, L. P.; PEREIRA, S. L.; MATIELO, M. D. et al. Efeito da densidade de estocagem no desenvolvimento inicial do acarábandeira (Pterophyllum scalare). Arquivo Brasileiro de Medicina Veterinária e Zootecnia, v.65, n.4, p.1176-1182. 2013.

HELRICH, K. Official methods of analysis of the association of official analytical. Chemists. Washington, DC. 1070 p. 1980.

INSTITUTO DE PESCA. In: Sanches, E. $G$. Instituto de pesca estuda peixes ornamentais. Disponível em: <http://www.pesca.sp.gov.br/noticia.php ?id_not=101>. Acesso em: 11 jul. 2013. JOLLY, C. M.; CLONTS, H. A. Economics of Aquaculture. New York: Food Products Press. USA. 319 p. 1993.
KOCA, S. B.; DILER, I.; DULLUC, A.; YIGIT, N. O.; BAYRAK, H. Effect of different feed types on growth and feed conversation ratio of angel fish (Pterophyllum scalare Lictenstein, 1823). Journal of Applied Biological Sciences, v.3, n.2, p.07-11. 2009.

KOROLEFF, F. Determination of nutrients. In: Grasshoff, K. (Ed.). Methods of seawater analysis. Weinhein: Verlag, p. 117-181. 1976.

LIMA, A. O. Aquicultura ornamental: $O$ potencial de mercado para algumas espécies ornamentais: Formas alternativas de diversificação da produção da aquicultura brasileira. Panorama da Aquicultura, Rio de Janeiro, v.13, p23-29. 2003.

LIMA, A. O.; BERNARDINO, G.; PROENÇA, C. E. M. Agronegócio de peixes ornamentais no Brasil e no mundo. Panorama da Aquicultura, v.11, p.14-24. 2001.

LUNA-FIGUEROA, J. Influencia de alimento vivo sobre la reproducición y crecimiento del pez ángel Pterophyllum scalare (Perciformes: Cichlidae). Acta Universitaria, Guanajuato, Gto, México, v.9, n.2, [s/p]. 1999.

MACKERETH, F. J. H., HERON, J., TALLING, J. F., Freshwater Biological Association. Water analysis: some revised methods for limnologists. 1978.

MIRES, D.; AMIT, Y.; AVNIMELECH, S. et al. Water quality in a recycled intensive fish culture system under field conditions. The Israeli Journal of Aquaculture, v.42, p.110-121, 1990.

OLIVEIRA, W. H. Proteína bruta, energia digestível e densidade de estocagem do ciclídeo ornamental acará-bandeira (Pterophyllum scalare). 2009. 75 f. Tese (Doutorado em ciência animal). Escola de Medicina Veterinária da Universidade Federal de Goiás. Goiânia - GO. 2009.

PÉREZ, E.; DIAZ, F.; ESPINA, S. Thermoregulatory behavior and critical thermal limits of angelfish Pterophyllum 
scalare (Lichtenstein) (Pisces: Cichlidae). Journal of Thermal Biology, Oxford, v.28, p.531 -537. 2003.

RIBEIRO, F. A. S.; RODRIGUES, L. A.; FERNANDES, J. B. K. Desempenho de juvenis de acará-bandeira (Pterophyllum scalare) com diferentes níveis de proteína bruta na dieta. Boletim do Instituto de Pesca, São Paulo, v. 3, n.2, p.195-203. 2007.

RIBEIRO, F. A. S.; PRETO, B. L.; FERNANDES, J. B. K. Sistemas de criação para o acará-bandeira (Pterophyllum scalare). Acta

Scientiarum. Animal Sciences, v. 30, p. 459-466, 2008.

RIBEIRO, F. A. S.; JORGE, P. H.; FERNANDES, J. B. K. et al. Densidade de estocagem para produção de acarábandeira em viveiros escavados em policultivo com camarão-da-Amazônia. Revista Caatinga, Mossoró, v.23, n.4, p.129-134. 2010.

RODRIGUES, L. A.; FERNANDES, J. B. K. Influência do processamento da dieta no desempenho produtivo do acará bandeira (Pterophyllum scalare). Acta Scientiarum. Animal Sciences, v.28, n.1, p. 113-119. 2006.

SALES, J.; JANSSENS, G. P. J. Nutrient requirements of ornamental fish. Aquatic Living Resources, Mountrouge, v.16, p.533-540. 2003.

SEAP - Secretária Especial de Aquicultura e Pesca. 2008. Peixe Ornamental contará com programa do governo federal. Disponível em: <http://www.presidencia.gov.br/estrutura _presidencia/seap> Acesso em: 24 jan. 2008.

SHIM, K. F.; CHUA, Y. L. Some studies on the protein requirement of the guppy, Poecilia reticulate (Peters). Journal of Aquariculture and Aquatic Science, Parkville, v.4, p.79-84. 1986.
SCHIMIDT, A. A. P. Piscicultura: a fonte divertida de proteínas. São Paulo: Ícone, 88p. 1988.

SIPAÚBA-TAVARES, L.H. Limnologia aplicada à aqüicultura. Jaboticabal: FUNEP, 70p. 1994.

STATSOFT INC. (2004). Statistica (data analysis software system), version 7.0.

TACON, A. G. J. Standard methods for the nutrition and feeding of farmed fish and shrimp. Argent laboratories press.,Washington, U.S.A.. 208 p. 1990.

TAKEUCHI, W.; WATANABE, T. Fish Nutrition and mariculture. Department of Aquatic Biosciences Tokyo University of Fisheries. JICA. Lampiran A. 230 p, 1988.

TIBBETTS, S. M.; CALL, S. P.; ANDERSON, D. M. Dietary protein requirement of juvenile American eel (Anguilla rostrata) fed practical diets. Aquaculture, v.186, n.1/2, p.145-155. 2000.

YANCEY, D. R.; MENEZES, J. R. R. Manual de criação de peixes. Instituto Campineiro de Ensino Agrícola. 117 p. 1983.

ZUANON, J. A. S.; SALARO, A. L.; BALBINO, E. M.; SARAIVA, A.; QUADROS, M.; FONTANARI, R. L. Níveis de proteína bruta em dietas para alevinos de acará-bandeira. Revista Brasileira de Zootecnia, Viçosa, v.35, n.5, p.1893-1896. 2006.

ZUANON, J. A. S.; SALARO, A. L.; MORAES, S. S. S.; ALVES, L. M. O.; BALBINO, E. M.; ARAUJO, E. S. Dietary protein and energy requirements of juvenile freshwater angelfish. Revista Brasileira de Zootecnia, v.38, n.6, p. 989-993. 2009. 